\title{
EXPRESSÃO E ATIVIDADE ENZIMÁTICA DE GLUTATIONA S-TRANSFERASE EM TECIDOS DE FÊMEAS DE Boophilus microplus
}

\author{
DANIELA R. J. DE FREITAS ${ }^{1}$; ITABAJARA DA S. VAZ JUNIOR; ${ }^{1,2}$ AOI MASUDA ${ }^{1,3}$
}

\begin{abstract}
FREITAS, D.R.J. DE; VAZ JUNIOR, I.DA S.; MASUDA, A. [Expression and enzymatic activity of glutathione s-transferase in tissues of Boophilus microplus females]. Expressão e atividade enzimática de glutationa s-transferase em tecidos de fêmeas de Boophilus microplus. Revista Brasileira de Parasitologia Veterinária, v. 17, n. 2, p. 99-104, 2008. Centro de Biotecnologia do Estado do Rio Grande do Sul, Universidade Federal do Rio Grande do Sul, C. P. 15005, Campus do Vale, Porto Alegre, RS 91501-970, Brasil. E-mail: ita@cbiot.ufrgs.br

Cellular detoxification and excretion enzymes are important to the maintenance of cellular homeostasis. In this work mRNA transcription, protein expression and enzymatic activity of Glutathione S-transferases (GSTs), enzymes involved in the excretion of endo and xenobiotic compounds were analyzed. These parameters are elements believed to protect cells against chemical toxicity and oxidative stress in different tissues (salivary gland, ovary and synganglion) from partially engorged females and engorged females of Boophilus microplus. The results presented showed elevated GST activity in partially engorged females. The enzymatic activity decreased during the preoviposition period in engorged females. GST mRNA transcription was detected in salivary glands and synganglion from partially engorged and engorged females, but not in ovary. The results of this work help to elucidate the role of GST in tick development and assist in the understanding of the importance of GST in tick females during the preparation for oviposition.
\end{abstract}

KEY WORDS: Rhipicephalus microplus, antioxidant; senescence; GST, preovipostion.

\section{RESUMO}

Enzimas de detoxificação e excreção celular são importantes para a manutenção da homeostase celular. Neste trabalho foi caracterizada a transcrição de mRNA, a expressão da proteína e a atividade enzimática de glutationa S-transfersases (GSTs), enzimas que atuam em rotas de excreção de substâncias endo e xenobióticas, protegendo as células contra toxicidade química e estresse, em diferentes tecidos (glândula salivar, ovário e singânglio) de fêmeas adultas semi-ingurgitadas e ingurgitadas do carrapato do bovino Boophilus microplus. Os resultados mostraram que a atividade de GST é mais alta em fêmeas semi-ingurgitadas e diminui em fêmeas ingurgitadas de acordo com o final do período de pré-postura. A expressão de mRNA de GST foi detectada em glândulas salivares e singânglios de fêmeas adultas semi-ingurgitadas e ingurgitadas, mas não em ovários. Estes dados podem ajudar a compreen-

\footnotetext{
${ }^{1}$ Centro de Biotecnologia do Estado do Rio Grande do Sul, Universidade Federal do Rio Grande do Sul, C. P. 15005, Campus do Vale, Porto Alegre, RS 91501-970, Brasil. E-mail: ita@cbiot.ufrgs.br

${ }^{2}$ Faculdade de Veterinária, UFRGS.

${ }^{3}$ Departamento de Biologia Molecular e Biotecnologia, UFRGS.
}

der melhor o papel de enzimas antioxidantes durante a preparação das fêmeas do carrapato para a postura.

PALAVRAS-CHAVE: Rhipicephalus microplus, antioxidante; envelhecimento; glutationa S-transferase, pré-postura.

\section{INTRODUÇÃO}

Carrapatos são capazes de parasitar quase todos os animais de importância econômica, causando grandes perdas em termos de produção (BOWMAN et al., 1996). O carrapato Boophilus microplus é um dos mais importantes ectoparasitas que afetam o gado bovino, causando grandes perdas econômicas (WILLADSEN, 2006), não só pelas doenças das quais é vetor como também pelos custos relacionados ao seu controle (JAMROZ et al. 2000). Estudos mais detalhados sobre sua fisiologia podem auxiliar no desenvolvimento de novos métodos de controle, e devido ao crescimento acelerado no número de populações resistentes de carrapato (DAVEY; GEORGE, 1998) tornou-se importante estudar mecanismos envolvidos em detoxificação celular (HEMINGWAY, 2000; KOSTAROPOULOS et al., 2001).

Entre as enzimas detoxificantes mais estudadas em diferentes organismos estão as glutationa S-transferases (GSTs), que 
pertencem a uma família multifuncional de enzimas que catalisam a conjugação da molécula de glutationa a várias outras moléculas, e possuem um papel fundamental em mecanismos de detoxificação intracelular de compostos endo e xenobióticos (CHELVANAYAGAM et al., 2001). GSTs desempenham vários papéis fisiológicos, tais como seqüestro e transporte de compostos hidrofóbicos endógenos, os quais incluem hormônios esteróides, heme, bilirubinas, ácidos da bile e seus metabólitos (SALINAS; WONG, 1999). A classificação das GST é bastante complexa e sujeita a discussão, mas muitos autores usam pelo menos nove grandes classes: quatro classes de GSTs de mamíferos - Alfa, Mu, Pi e Teta (MANNERVIK; WIDERSTEN, 1995); as classes presentes em humanos Kappa (PEMBLE et al., 1996) e Zeta (BOARD et al., 1997); as classes Sigma em cefalópodes e artrópodes, a classe Fi de plantas, e a classe Delta de insetos (também referida como classe Teta) (BOARD et al., 1997). Outros autores têm sugerido uma classificação alternativa para GSTs de insetos, dividindo-as em três classes distintas, I, II e III. Enzimas da Classe I pertencentes à Classe Delta, que é específica de insetos; enzimas Classe II são principalmente membros da classe Sigma e estão presentes em dípteros (BEALL et al., 1992; AGIANIAN et al., 2003); e enzimas Classe III têm sido implicadas em detoxificação, e em particular em conferir resistência a vários inseticidas (AGIANIAN et al., 2003).

Em mosquito (KETTERMAN et al., 2001) e moscas (WEI et al., 2001) uma alta atividade de GST tem sido relacionada à resistência a pesticidas. Em outro díptero, Chironomus tentans, Rakotondravelo et al. (2006) também mostraram altos níveis de atividade de GST em resposta a diferentes pesticidas. Le Goff et al. (2006) mostrou que xenobióticos causam um aumento na expressão de genes de GSTs em Drosophila melanogaster. Em ácaros a função e importância das GSTs é bem menos conhecida do que nos insetos. Especificamente no carrapato B. microplus já foi descrita a clonagem e caracterização de duas GSTs, uma de larvas (HE et al., 1999) e outra de glândulas salivares de fêmeas semi-ingurgitadas (ROSA DE LIMA et al., 2002). Freitas et al. (2006) caracterizaram a atividade de GST em ovos e larvas de B. microplus durante o desenvolvimento embrionário e larval.

Neste trabalho foram analisadas a atividade enzimática, a transcrição e expressão protéica de uma GST presente em tecidos de fêmeas de B. microplus, relacionando o papel da GST como enzima antioxidante durante o envelhecimento e durante o período de pré-postura.

\section{MATERIAL E MÉTODOS}

\section{Carrapatos}

Fêmeas adultas ingurgitadas de B. microplus (isolado Porto Alegre, cepa livre de Babesia spp. e Anaplasma spp., mantidos por passagem em bovinos estabulados no Laboratório de Entomozooses da Faculdade de Veterinária da Universidade Federal do Rio Grande do Sul) foram experimentalmente mantidas em laboratório a $28^{\circ} \mathrm{C}$ e $85 \%$ de umidade relativa até a postura, e sua fase de vida parasitária foi completada em bovinos confinados em estábulo.
As fêmeas selecionadas para os experimentos foram classificadas de acordo com seu peso: de 180 a 200 mg as fêmeas foram consideradas semi-ingurgitadas e fêmeas pesando 350 mg foram consideradas ingurgitadas.

\section{Dissecação de tecidos e preparação dos extratos}

Fêmeas semi-ingurgitadas e ingurgitadas foram lavadas com etanol $70 \%$ e sua superfície dorsal foi dissecada com uma lâmina de bisturi em tampão 100 mM Tris-HCl 5 mM EDTA pH 8,0. Glândulas salivares, ovários e singânglios foram separados e lavados no mesmo tampão. Após a dissecação, os órgãos foram dissociados no mesmo tampão, centrifugados a $15.000 \mathrm{x} g$ por 5 min e, os sobrenadantes foram incubados em banho de gelo. A atividade enzimática dos extratos foi testada imediatamente para a determinação da atividade enzimática de GST com um substrato específico (1cloro-2, 4-dinitrobenzeno (CDNB), Sigma) para GSTs. O restante dos extratos era congelado a $-70^{\circ} \mathrm{C}$ para os ensaios de western blot.

\section{Ensaio de atividade de GST}

A atividade de GST dos extratos obtidos a partir dos órgãos dissecados foi determinada segundo o método de Habig et al. (1974), usando 1-cloro-2, 4-dinitrobenzeno (CDNB) (Sigma) como substrato. Noventa microlitros da reação de mistura (50 mM CDNB em metanol, $5 \mathrm{mM}$ glutationa reduzida em 100 mM Tris-HCl pH 7,5) e $10 \mu$ l de extrato em 100 $\mathrm{mM}$ Tris-HCl pH 7,5 foram testados em uma placa de 96 poços, de acordo com Da Silva Vaz Jr. et al. (2004b). Como controle negativo foi usado tampão com CDNB e GSH sem a enzima. A concentração do produto formado foi calculada usando o coeficiente de extinção de $9,6 \mathrm{mM}^{-1}$. $\mathrm{cm}^{-1}$ para S(2,4 - dinitrofenil glutationa) (MANERVICK; WIDERSTEN, 1995). As concentrações de proteína dos extratos foram determinadas pelo método de Bradford (BRADFORD, 1976) usando albumina sérica bovina como padrão. Os ensaios foram feitos em duplicata e os resultados foram expressos como a média calculada e o desvio padrão de três experimentos independentes.

\section{Western blot}

Para a análise por western blot $100 \mu$ g de extrato de tecidos foram incubados por 2 min com $15 \mu$ l de Glutationa Sepharose 4B (Amersham Biosciences), centrifugados a $15.000 \times \mathrm{g}$ por $5 \mathrm{~min}$, e os sobrenadantes foram descartados. Após cinco lavagens em tampão PBS, as resinas contendo as amostras foram incubadas a temperatura ambiente em tampão contendo 2\% SDS, $250 \mathrm{mM}$ Tris pH 6,8, 0.025\% azul de bromofenol, $5 \%$ glicerol, $10 \% \beta$-mercaptoetanol e 5 M uréia e a mistura foi submetida a eletroforese em gel de poliacrilamida com SDS (SDS-PAGE - 14\%) (LAEMMLI, 1970). As amostras foram transferidas para membranas de nitrocelulose a $70 \mathrm{~V}$ por $1 \mathrm{~h}$ a $4^{\circ} \mathrm{C}$ em tampão $12 \mathrm{mM}$ carbonato $\mathrm{pH}$ 9,9 (DUNN, 1986). As membranas de nitrocelulose foram bloqueadas com solução BLOTTO (5\% leite desnata- 
do em PBS, $\mathrm{pH} 7,2)$ por $1 \mathrm{~h}$ a temperatura ambiente. Soro policlonal de coelho anti-GST (1:1000) (ROSA DE LIMA et al., 2002) foi incubado com BLOTTO a $4^{\circ} \mathrm{C}$ por $16 \mathrm{~h}$. Após as lavagens em BLOTTO, anticorpo de cabra anti-IgG de coelho conjugado com peroxidase foi incubado com as nitroceluloses por $1 \mathrm{~h}$ a temperatura ambiente. Após três lavagens com PBS, a reação foi revelada com 5 mg de 3,3'diaminobenzidina (DAB), $150 \mu \mathrm{l}$ de $\mathrm{H}_{2} \mathrm{O}_{2}$ e $100 \mu \mathrm{l}$ de $1 \%$ $\mathrm{CoCl}_{2}$ em $30 \mathrm{ml}$ de PBS e parada com água.

\section{Isolamento de RNA poli A+ e RT-PCR}

RNA poli A+ foi isolado de órgãos de fêmeas semiingurgitadas e ingurgitadas de $B$. microplus durante o período de pré-postura (0, 1,2 e 3 dias após a coleta). Para o isolamento de RNA poli A+ foi usado o kit de purificação Quick Prep Micro mRNA (Amersham Biosciences), de acordo com as instruções do fabricante. Do mRNA obtido, 500 ng foi submetido a reação de transcrição reversa $(\mathrm{RT})$ a $37^{\circ} \mathrm{C}$ na presença de oligo-dT (Amersham Biosciences) e SuperScript II transcriptase (Invitrogen), de acordo com as instruções do fabricante. Amplificações por PCR foram realizadas usando $1 / 20$ da reação de RT, 20 pmol de primers e 5 U de Taq Polimerase (Cenbiot - UFRGS) em um volume final de $50 \mu$ l. Os seguintes primers foram usados para amplificar o cDNA da GST: GSTfor - 5' CGACCACGACACAAAGATGG 3' e GSTrev - 3' ACAGGAACCCGATACTGATTTC 5' (DA SILVA VAZ JR et al., 2004a). Para amplificar o cDNA de actina foram usados os primers BmAct2 - 5' GGGGTGTAGA AGGAAGG3' e BmAct3 - 3' GCATCCACGAGACCACG 5' (Da SILVA VAZ JR et al., 2005). As amostras foram desnaturadas por 10 min a $94{ }^{\circ} \mathrm{C}$ e a amplificação foi feita através de 35 ciclos de $30 \mathrm{~s}$ a $94^{\circ} \mathrm{C}, 30 \mathrm{~s}$ a $50^{\circ} \mathrm{C}$ e 3 min a 72 ${ }^{\circ} \mathrm{C}$, com um ciclo de extensão final de 30 s a $50^{\circ} \mathrm{C}$ e 10 min a $72{ }^{\circ} \mathrm{C}$. A amplificação obtida a partir dos primers projetados baseados na seqüência de GST resultou em um amplificado de 663 pb; os primers específicos para a seqüência de actina amplificaram um fragmento de $337 \mathrm{bp}$, que foi usado como controle positivo. Controles negativos para as reações de RT e PCR foram usadas em todos os ensaios.

\section{Análise estatística}

Os resultados foram apresentados como média \pm desvio padrão. Para a análise estatística foi usado o teste-t para comparação entre 2 grupos. O valor de significância foi de $p<0,05$.

\section{RESULTADOS}

\section{Expressão de proteína e atividade enzimática}

Em glândulas salivares a atividade de GST foi de 1,33 $\pm 0,28 \mu \mathrm{mol} / \mathrm{min} / \mathrm{mg}$ proteína; em ovário apresentou 0,59 \pm 0,11 $\mu \mathrm{mol} / \mathrm{min} / \mathrm{mg}$ proteína; e em singânglio apresentou $1,18 \pm 0,18$ $\mu \mathrm{mol} / \mathrm{min} / \mathrm{mg}$ proteína em fêmeas semi-ingurgitadas $(\mathrm{p}<0,05)$. A expressão da proteína foi detectada por western blot em todos os extratos de tecidos usando soro de coelho anti-GST (Figura 1).

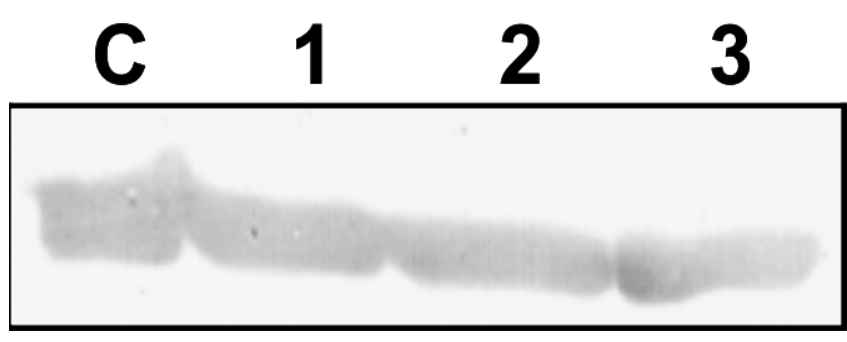

Figura 1. Expressão de proteína de GST em fêmeas semi-ingurgitadas de Boophilus microplus. Western blot de extrato de tecidos. Soro de coelho imunizado com GST recombinante foi usado como sonda. C, controle (GST recombinante purificada).

Tabela 1. Atividade enzimática de glutationa $S$-transferase (GST) em extratos de tecidos de fêmeas ingurgitadas de Boophilus microplus, em diferentes tempos após coleta (resultados de três experimentos independentes).

\begin{tabular}{ccccc}
\hline Tecido & \multicolumn{4}{c}{ Atividade de GST ( $\mu \mathrm{mol} / \mathrm{min} / \mathrm{mg}$ proteína)(média \pm d.p.) } \\
\cline { 2 - 5 } & $0 \mathrm{~h}$ & $24 \mathrm{~h}$ & $48 \mathrm{~h}$ & $72 \mathrm{~h}$ \\
\hline Glândula & $0,655 \pm 0,052^{\mathrm{A}}$ & $0,449 \pm 0,012^{\mathrm{B}}$ & $0,304 \pm 0,050^{\mathrm{C}}$ & $0,254 \pm 0,062^{\mathrm{C}}$ \\
salivar & & & & \\
Ovário & $0,459 \pm 0,095^{\mathrm{A}}$ & $0,357 \pm 0,049^{\mathrm{A}}$ & $0,341 \pm 0,112^{\mathrm{B}}$ & $0,181 \pm 0,008^{\mathrm{B}}$ \\
Singânglio & $0,578 \pm 0,073^{\mathrm{A}}$ & $0,387 \pm 0,021^{\mathrm{B}}$ & $0,378 \pm 0,103^{\mathrm{B}}$ & $0,416 \pm 0,086^{\mathrm{B}}$ \\
\hline
\end{tabular}

Valores seguidos de letras diferentes nas linhas apresentam diferença estatística $(p<0,05)$.

No dia zero, a atividade de GST foi mais alta $(\mathrm{p}<0,05)$ em glândulas salivares do que nos outros tecidos de fêmeas ingurgitadas (Tabela 1), 0,66, 0,46 e 0,58 $\mu \mathrm{mol} / \mathrm{min} / \mathrm{mg}$ proteína em glândula salivar, ovário e singânglio, respectivamente. Os extratos dos dias 2 e 3 de ovários e glândulas salivares apresentaram uma significativa queda $(\mathrm{p}<0,05)$ na atividade de GST quando comparados ao dia 0 . Em singânglio, a atividade de GST diminuiu significativamente no dia 1 e após (dias 2 e 3) se manteve estável (comparável ao dia 1) ( $p<0,05)$. A análise de western blot de GST nos órgãos de fêmeas ingurgitadas mostrou a expressão de proteína em todos os tecidos e em todos os tempos após a coleta (Figura 2).

\section{Transcrição}

A transcrição de GST nos órgãos foi detectada nas glândulas salivares e nos singânglios de fêmeas semi-ingurgitadas e de fêmeas nos dias 0 e 1 do período de pré-postura (Figura

\section{Glândulas salivares

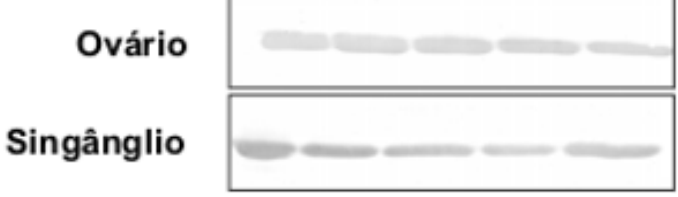

Figura 2. Expressão de proteína de GST em fêmeas ingurgitadas de Boophilus microplus. Western blot de extrato de tecidos. Soro de coelho imunizado com GST recombinante foi usado como sonda. C, controle (GST recombinante purificada). 
$\begin{array}{lllllllllllllllll}1 & 2 & 3 & 4 & 5 & 6 & 7 & 8 & 9 & 10 & 11 & 12 & 13 & 14 & 15 & 16 & 17\end{array}$

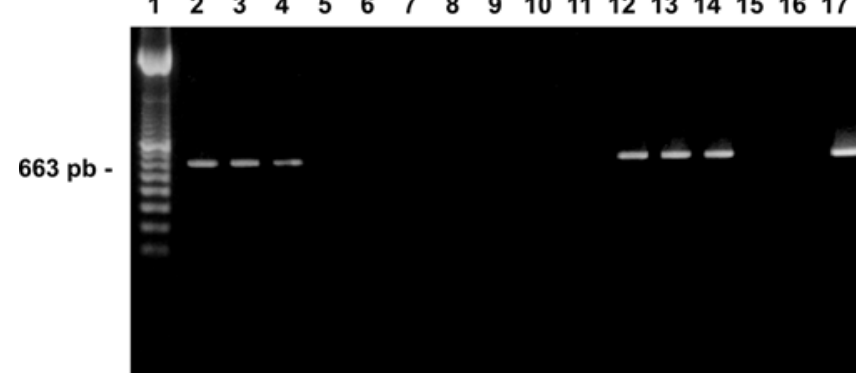

Figura 3. RT-PCR de diferentes tecidos de fêmeas adultas semiingurgitadas e ingurgitadas de Boophilus microplus. Linha 1, marcador de massa molecular 100 pb; linha 2, glândulas salivares de fêmeas semi-ingurgitadas; linhas 3 a 6, glândulas salivares de fêmeas de 0 a 3 dias do período de pré-postura; linha 7, ovários de fêmeas semiingurgitadas; linhas 8 a 11, ovários de fêmeas de 0 a 3 dias do período de pré-postura; linha 12, singânglios de fêmeas semi-ingurgitadas; linhas 13 a 16, singânglios de fêmeas de 0 a 3 dias do período de pré-postura; linha 17 , controle positivo do PCR, amplificado a partir de um cDNA de GST clonado.

3, linhas 2, 3 e 4 e linhas 12, 13 e 14). Em ovários de fêmeas semi-ingurgitadas e ingurgitadas não foi detectada expressão de mRNA (Figura 3, linhas 7, 8 e 9). Devido a degradação de mRNA em glândulas salivares, ovários e singânglios de 2 e 3 dias (Figura 3, linhas 5, 6, 10, 11, 15 e 16) não foi possível verificar a transcrição nestes órgãos (dados não mostrados).

\section{DISCUSSÃO}

Os organismos possuem uma série de mecanismos que permitem sua sobrevivência no ambiente em uma ampla faixa de temperatura, umidade, salinidade, oxigênio e radiação. Quando a célula sofre um dano oxidativo, uma série de eventos ocorre, tais como hidrólise de DNA e proteína e peroxidação de lipídeos. Estes danos são gerados por espécies reativas de oxigênio (ROS - reactive oxygen species). Para minimizar o dano oxidativo aos componentes celulares todos os organismos desenvolveram uma série de defesas antioxidantes, tais como moléculas ligantes como GSH (SIES, 1999) ou enzimas, como SOD (superóxido dismutase), CAT (catalase), GPx (glutationa peroxidase) (RIKANS; HORNBROOK, 1997) e GSTs (KETTERER et al., 1983). Estudos mostram que a atividade de antioxidantes aumenta com o aumento de ROS em larvas de tricóptero (BARATA et al., 2005).

Muitos destes mecanismos de proteção estão sendo caracterizados em artrópodes. A seleção de populações resistentes a drogas é, de forma geral, também baseada em uma série de mecanismos moleculares que permitem a essas populações sobreviverem à exposição a estas drogas e estes mecanismos estão, em sua grande parte, ligados à ativação de rotas metabólicas envolvidas na proteção contra estresse oxidativo (HEMINGWAY, 2000; KOSTAROPOULOS et al., 2001), daí a importância de estudar os mecanismos fisiológicos que levam à proteção do carrapato contra estresse oxidativo causado por produtos químicos ou pelo ambiente.
As glândulas salivares foram selecionadas uma vez que já havia sido relatada atividade de GST em fêmeas semiingurgitadas (ROSA DE LIMA et al., 2002); ovário foi selecionado por ser um órgão de alta atividade metabólica, onde uma série de eventos fisiológicos envolvidos com a formação do ovo está ocorrendo. O singânglio foi incluído nesta investigação por ser um órgão que desempenha a função de sistema nervoso central, além de atuar na oogênese produzindo um fator estimulador para o desenvolvimento do ovo (OLIVER et al., 1992). A atividade de GST em órgãos de fêmeas semiingurgitadas foi mais alta que a atividade de tecidos de fêmeas ingurgitadas, independente do tempo após a coleta. Estas atividades foram similares ao observado para outros artrópodes, tais como o afídeo Rhopalosiphum padi e outros insetos (MUKANGANYAMA et al., 2003). Uma hipótese para a atividade mais alta de GST nas fêmeas semi-ingurgitadas está no fato de que estas estão ingerindo sangue e, para evitar ROS geradas pela alimentação, precisariam de uma mecanismo anti-oxidante mais ativo e eficiente.

A atividade de GST em todos os tecidos coletados no dia 0 de fêmeas ingurgitadas foi significativamente maior que nos outros dias (Tabela 1). A atividade de GST em ovário e glândulas salivares decresce continuamente, enquanto em singânglio a atividade decresce no dia 1 após a coleta e se mantém no mesmo nível nos dias subseqüentes. É interessante também observar que a atividade de GST em singânglio foi maior que em outros órgãos, indicando que a manutenção da alta atividade de antioxidantes por longos períodos parece ser importante para prevenir dano oxidativo em um tecido com importante função nervosa e endócrina.

Não foi encontrada transcrição no ovário. Em compensação, por western blot foi verificada a expressão da proteína em todos os tecidos, inclusive em ovário. Isto pode indicar que a síntese de GST não ocorre neste órgão, mas em outros e é transportada para o mesmo, entretanto não podemos descartar diferenças entre a especificidade do Western-blot com a do RT-PCR. Foi observada a transcrição em glândulas salivares e singânglio de fêmeas ingurgitadas 0 e 1 dias após a coleta, mas nos outros dias não foi possível observar transcrição devido a degradação de mRNA nos tecidos. Esta degradação não ocorreu durante a extração e sim in vivo, conforme observado pela análise da integridade do DNA genômico (dados não mostrados).

As GSTs estão presentes em quase todos os organismos e são um importante mecanismo de detoxificação intracelular (PAPADOPOULOS et al., 2004), mas apesar disto relativamente pouco conhecimento existe sobre os mecanismos de ação de GSTs sobre substratos endógenos, (RANSON; HEMINGWAY, 2005). Sabe-se, no entanto, que entre as funções não associadas diretamente com detoxificação estão o reparo de macromoléculas oxidadas por espécies reativas de oxigênio, regeneração de proteínas S-tioladas e biossíntese de metabólitos fisiologicamente importantes (ARMSTRONG, 1997; SHEEHAN et al., 2001). Adewale e Afolayan (2005) caracterizaram a distribuição de GST nos principais órgãos 
do caranguejo de rio africano (Macrobrachium vollenhovenii) a fim de encontrar qual o órgão mais importante para a detoxificação de compostos xenobióticos e encontraram uma alta atividade em hepatopâncreas.

Apesar da presença de sistemas antioxidantes de defesa, muitos danos não podem ser totalmente evitados e são acumulados ao longo do ciclo de vida celular, e tem-se proposto que estes danos ao DNA, proteínas e lipídeos têm um papel chave no desenvolvimento de doenças dependentes da idade em humanos e envelhecimento de forma geral (REBRIN et al., 2004). Além de dano oxidativo pelo ambiente, dano oxidativo endógeno gerado pelos produtos de metabolismo do alimento ingerido pelo carrapato e a formação dos ovos nas gônadas também são significativos. E, juntamente com estes processos, ocorre o envelhecimento concomitante da fêmea ingurgitada, que culminará com sua morte após a postura dos ovos. Rebrin et al. (2004) demonstrou em moscas que a quantidade de antioxidantes aumenta durante o seu envelhecimento. Os resultados obtidos neste trabalho sugerem que GST pode ter uma função importante durante o envelhecimento da fêmea e durante o período de pré-postura, atuando como um detoxificador e antioxidante.

\section{REFERÊNCIAS BIBLIOGRÁFICAS}

ADEWALE, I.O.; AFOLAYAN, A. Purification and catalytic properties of glutathione transferase from the hepatopancreas of crayfish Macrobrachium vollenhovenii (herklots). Journal of Biochemistry and Molecular Toxicology, v. 18, n. 6, p. 332-344, 2004.

AGIANIAN, B.; TUCKER, P.A.; SCHOUTEN, A.; LEONARD, K.; BULLARD, B.; GROS, P. Structure of a Drosophila sigma class glutathione $\mathrm{S}$-transferase reveals a novel active site topography suited for lipid peroxidation products. Journal of Molecular Biology, v. 326, n. 1, p. 151-165, 2003.

ARMSTRONG, R.N. Structure, catalytic mechanism, and evolution of the glutathione S-transferase. Chemical Research in Toxicology, v. 10, n. 1, p. 2-18, 1997.

BARATA, C.; LEKUMBERRI, I.; VILA-ESCALE, M.; PRAT, N.; PORTE, C. Trace metal concentration, antioxidant enzyme activities and susceptibility to oxidative stress in the tricoptera larvae Hydropsyche exocellata from the Llobregat river basin (NE Spain). Aquatic Toxicology, v. 74, n. 1, p. 3-19, 2005.

BEALL, C.; FYRBERG, C.; SONG, S.; FYRBERG, E. Isolation of a Drosophila gene encoding glutathione Stransferase. Biochemical Genetics, v. 30, n. 9-10, p. 515527, 1992.

BOARD, P.G.; BAKER, R.T.; CHELVANAYAGAM, G.; JERMIIN, L.S. Zeta, a novel class of glutathione transferases in a range of species from plants to humans. Biochemical Journal, v. 328, n. 3, p. 929-935, 1997.

BOWMAN, A.S.; DILLWITH, J.W.; SAUER, J.R. Tick salivary prostaglandins: presence, origin and significance. Parasitology Today, v. 12, n. 10, p. 388-396, 1996.
BRADFORD, M.M. A rapid and sensitive method for the quantification of microgram quantities of protein utilizing the principle of protein-dye binding. Analytical Biochemistry, v. 72, n. 1-2,p. 248-254, 1976.

CHELVANAYAGAM, G.; PARKER, M.W.; BOARD, P.G. Fly fishing for GSTs: a unique nomenclature for mammalian and insect glutathione transferases. Chemico-Biological Interactions, v. 133, n.1-3, p. 256-260, 2001.

DA SILVA VAZ JR. I.; IMAMURA S.; OHASHI K.; ONUMA M. Cloning, expression and partial characterization of a Haemaphysalis longicornis and a Rhipicephalus appendiculatus glutathione S-transferase. Insect Molecular Biology, v. 13, n. 3, p. 329-335, 2004.

DA SILVA VAZ JR., I.; TORINO LERMEN, T.; MICHELON, A.; FERREIRA, C.A.S.; FREITAS, D.R.J.; TERMIGNONI, C.; MASUDA, A. Effect of acaricides on the activity of a Boophilus microplus glutathione Stransferase. Veterinary Parasitology, v. 119, n. 2-3, p. 237245, 2004.

DA SILVA VAZ JR., I.; IMAMURA, S.; NAKAJIMA, C.; DE CARDOSO, F.C.; FERREIRA, C.A.; RENARD, G., MASUDA, A.; OHASHI, K.; ONUMA, M. Molecular cloning and sequence analysis of cDNAs encoding for Boophilus microplus, Haemaphysalis longicornis and Rhipicephalus appendiculatus actins. Veterinary Parasitology, v. 127, n. 2, p. 147-155, 2005.

DAVEY, R.B.; GEORGE, J.E. In vitro and in vivo evaluations of a strain of Boophilus microplus (Acari: Ixodidae) selected for resistance to permethrin. Journal of Medical Entomology, v. 35, n. 6, p. 1013-1019, 1998.

DUNN, S.D. Effects of the modification of transfer buffer composition and the renaturation of proteins in gels on the recognition of proteins on Western-blot by monoclonal antibodies. Analytical Biochemistry, v. 157, n. 1, p. 144 153, 1986.

FREITAS, D.R.; ROSA, R.M., MORAES, J.; CAMPOS, E.; LOGULLO, C.; DA SILVA VAZ JR, I.; MASUDA, A. Relationship between glutathione S-transferase, catalase, oxygen consumption, lipid peroxidation and oxidative stress in eggs and larvae of Boophilus microplus (Acarina: Ixodidae). Comparative Biochemistry and Physiology part A, v. 146, n. 4, p.688-694, 2007.

HABIG, W.H.; PABST, M.J.; JAKOBY, W.B. Glutathione Stransferases. The first enzymatic step in mercapturic acid formation. Journal of Biological Chemistry, v. 249, n. 22, p. 7130-7139, 1974.

HE, H.; CHEN, A.C.; DAVEY, R.B.; IVIE, G.W.; GEORGE, J.E. Characterization and molecular cloning of a glutathione S-transferase gene from the tick, Boophilus microplus (Acari: Ixodidae). Insect Biochemistry and Molecular Biology, v. 29, n. 8, p. 737-743, 1999.

HEMINGWAY, J. The molecular basis of two contrasting metabolic mechanisms of insecticide resistance. Insect Biochemistry and Molecular Biology, v. 30, n. 11, p. 1009 1015, 2000. 
JAMROZ, R.C.; GUERRERO, F.D.; PRUETT, J.H.; OEHLER, D.D.; MILLER, R.J. Molecular and biochemical survey of acaricide resistance mechanisms in larvae from Mexican strains of the southern cattle tick, Boophilus microplus. Journal of Insect Physiology, v. 46, n. 5, p. 685695, 2000.

KETTERER, B.; COLES, B.; MEYER, D.J. The role of glutathione in detoxification. Environmental Health Perspectives, v. 49, p. 59-69, 1983.

KETTERMAN, A.J.; PROMMEENATE, P.; BOONCHAUY, C.; CHANAMA, U.; LEETACHEWA, S.; PROMTET, N.; PRAPANTHADARA, L. Single amino acid changes outside the active site significantly affect activity of glutathione S-transferases. Insect Biochemistry and Molecular Biology, v. 31, n.1, p. 65-74, 2001.

KOSTAROPOULOS, I.; MANTZARI, A.E.; PAPADOPOULOS, A.I. Alterations of some glutathione $S$-transferase characteristics during the development of Tenebrio molitor (Insecta: Coleoptera). Insect Biochemistry and Molecular Biology, v. 26, n. 8-9, p. 963-969, 1996.

KOSTAROPOULOS, I.; PAPADOPOULOS, A.I.; METAXAKIS, A.; BOUKOUVALA, E.; PAPADOPOULOU-MOURKIDOU, E. Glutathione Stransferase in the defence against pyrethroids in insects. Insect Biochemistry and Molecular Biology, v. 31, n. 4-5, p. 313-319, 2001.

LAEMMLI, E.K. Cleavage of structural proteins during the assembly of the head of bacteriophage T4. Nature, v. 227, n.5259, p. 680-685, 1970.

LE GOFF, G.; HILLIOU, F.; SIEGFRIED, B.D.; BOUNDY, S.; WAJNBERG, E.; SOFER, L.; AUDANT, P.; FFRENCHCONSTANT, R.H.; FEYEREISEN, R. Xenobiotic response in Drosophila melanogaster: sex dependence of P450 and GST gene induction. Insect Biochemistry and Molecular Biology, v. 36, n. 8, p.674-682, 2006.

MANNERVICK, B.; WIDERSTEN, M. Human glutathione transferases: tissue distribution, structure and funcional properties. In: PACIFIC, G. M; FRACCHIA, G. N. (eds). Advances in Drug Metabolism in Man. Brussels:EUR 15439, ECDGX11-E4, 1995. p. 408-459.

MUKANGANYAMA, S.; FIGUEROA, C.C.; HASLER, J.A.; NIEMEYER, H. M. Effects of DIMBOA on detoxification enzymes of the aphid Rhopalosiphum padi (Homoptera: aphididae). Journal of Insect Physiology, v. 49, n. 3, p. 223-229, 2003.

OLIVER, J.H. JR; ZHU, X.X.; VOGEL, G.N.; DOTSON, E.M. Role of synganglion in oogenesis of the tick Ornithodoros parkeri (Acari: Argasidae). Journal of Parasitology, v. 78, n. 1, p. 93-98, 1992.

PAPADOPOULOS, A.I.; POLEMITOU, I.; LAIFI, P.; YIANGOU, A.; TANANAKI, C. Glutathione S-transferase in the insect Apis mellifera macedonica kinetic characteristics and effect of stress on the expression of GST isoenzymes in the adult worker bee. Comparative Biochemistry and Physiology part C: Toxicology and Pharmacology, v. 139, n. 1-3, p. 93-97, 2004.

PEMBLE, S.E.; WARDLE, A.F.; TAYLOR, J.B. Glutathione S-transferase class Kappa: characterization by the cloning of rat mitochondrial GST and identification of a human homologue. Biochemical Journal, v. 319, n. 3, p. 749-754, 1996.

RANSON, H.; HEMINGWAY, J. Mosquito glutathione transferases. Methods in Enzymology, v. 401, p. 226-241, 2005.

RAKOTONDRAVELO, M.L.; ANDERSON, T.D.; CHARLTON, R.E.; ZHU, K.Y. Sublethal effects of three pesticides on activities of selected target and detoxification enzymes in the aquatic midge, Chironomus tentans (diptera: chironomidae). Archives of Environmental Contamination and Toxicology, v. 51, n. 3, p. 360-366, 2006.

REBRIN, I.; BAYNE, A.C.; MOCKETT, R.J.; ORR, W.C.; SOHAL, R.S. Free aminothiols, glutathione redox state and protein mixed disulphides in aging Drosophila melanogaster. Biochemical Journal, v. 382, n. 1, p.131136, 2004.

RIKANS, L.E.; HORNBROOK, K.R. Lipid peroxidation, antioxidant protection and aging. Biochemica and Biophysica Acta, v. 1362, n. 2-3, p. 116-127, 1997.

ROSA DE LIMA, M.F.; FERREIRA, C.A. S.; FREITAS, D.R.J.; VALENZUELA, J.G.; MASUDA, A. Cloning and partial characterization of a Boophilus microplus (Acari: Ixodidae) Glutathione S-transferase. Insect Biochemistry and Molecular Biology, v. 32, n. 7, p. 747-754, 2002.

SALINAS, A.E.; WONG, M.G. Glutathione S-transferases a review. Current Medicinal Chemistry, v. 6, n. 4, p. 279309, 1999.

SIES, H. Glutathione and its role in cellular functions. Free Radical Biology \& Medicine, v. 27, n. 9-10, p.916-921, 1999.

SHEEHAN, D.; MEADE, G.; FOLEY, V.M.; DOWD, C.A. Structure, function and evolution of glutathione transferase: implications for classification of non-mammalian members of an ancient enzyme superfamily, Biochemical Journal, v. 360, n. 1, p.1-16. 2001.

WEI, S.H.; CLARK, A.G.; SYVANEN, M. Identification and cloning of a key insecticide-metabolizing glutathione Stransferase (MdGST-6A) from a hyperinsecticide-resistant strain of the housefly Musca domestica. Insect Biochemistry and Molecular Biology, v. 31, n. 12, p.1145-1153, 2001.

WILLADSEN, P. Tick control: thoughts on a research agenda. Veterinary Parasitology, v. 138, n. 1-2, p. 161-168, 2006.

Recebido em 12 de julho de 2007.

Aceito para publicação em 30 de junho de 2008. 